\title{
Mobile Coverage in Rural Sweden: Analysis of a Comparative Measurement Campaign
}

\author{
P. G. Sudheesh $\mathbb{D}^{1}$ and Jaap van de Beek $\mathbb{D}^{2}$ \\ ${ }^{1}$ Department of Electronics and Communication, Manipal Institute of Technology, MAHE, Udupi, India \\ ${ }^{2}$ Department of Computer Science, Electrical and Space Engineering, Luleå University of Technology, Luleå, Sweden
}

Correspondence should be addressed to P. G. Sudheesh; pgsudheesh@gmail.com

Received 9 September 2020; Revised 6 November 2020; Accepted 10 December 2020; Published 5 January 2021

Academic Editor: Peter Brida

Copyright (c) 2021 P. G. Sudheesh and Jaap van de Beek. This is an open access article distributed under the Creative Commons Attribution License, which permits unrestricted use, distribution, and reproduction in any medium, provided the original work is properly cited.

\begin{abstract}
Under the umbrella of $1 \mathrm{G}$ to $5 \mathrm{G}$, different technologies have been used to provide mobile communication. Various technologies are being proposed to bring a person in remote area under coverage. However, a statistical analysis on what these users get from already existing technologies has not been carried out. We fill this gap by carrying out such a study using a measurement campaign, where we present a framework for analyzing mobile signal strength experienced at the user end. Measurements are taken throughout the Norbotten county, the northernmost county in Sweden, using mobile phones recording various parameters at regular intervals. Based on measured signal strength, a coverage map has been made via inverse distance weighting (IDW) interpolation. Based on the coverage map, various analyses are carried out on signal strength over residential areas and roads of Norrbotten. Overall, we lay a framework to analyze and quantify the effect of signal strength on users.
\end{abstract}

\section{Introduction}

Earlier this year, 3rd Generation Partnership Project (3GPP) released the first versions of its $5 \mathrm{G}$ new radio (NR) standard, first as a non-stand-alone mode, and later the stand-alone mode. For a while now, it has become clear that this standard essentially has its focus on the urban areas. Use cases and scenarios invariably address dense network environments, small cells, and a large number of mobile users per unit area.

Naturally, concerns have been raised by stakeholders representing rural values, needs, and interests. With everdecreasing cell sizes, how will areal coverage be guaranteed is based not only on the old standards and systems but also on new essential $5 \mathrm{G}$ functionalities as network slicing, ultralow latencies, and massive bandwidth [1].

The first 5G testbed in Norrbotten, Sweden, was tested in June 2019 [2] and, therefore, for majority of population, 5G network is still not accessible. Also, 5G handsets are also not so widely available in the market. Hence, a major portion of the population is still using $2 \mathrm{G}, 3 \mathrm{G}$, and/or $4 \mathrm{G}$ network for mobile communication. Therefore, expanding coverage area and bringing more people under mobile coverage map require network planning and installing new base stations.

However, installing terrestrial base stations (BS) and providing backhaul are subject to the revenue earned from the mobile users [3]. Therefore, installing a terrestrial base station and associated backhaul in "not so popular" areas is not attractive from an economical point of view. This in turn results in deployment of lesser number of base stations or even absence of base stations in such sparsely populated areas.

As a result, the people in these areas are subjected to poor or absence of coverage. It is widely known that larger operators and stakeholders of telecom industry do not want to put up new base stations in nonprofitable areas. In other words, the telecom companies hold the right not to put up new base stations in places that are not profitable to them [4]. It is rather interesting that the notion of full coverage is limited only to the areas defined by the operators.

To overcome these limitations and provide full coverage irrespective of population density, different solutions like positioning UAV BS [5] and new allocation spectrum [6] are 
considered. Swedish regulators have come up with new $700 \mathrm{MHz}$ band that focuses on lesser coverage areas [6]. To this end, Swedish authorities and especially Norrbotten, the northernmost county in Sweden, wanted to identify and focus on the areas with no or poor coverage [4]. Neither the coverage map from operators nor the location of base stations was available to researchers. To this end, we generate a coverage map generated using crowd sourced measurements across Norrbotten.

It is found in [7] that mobile coverage is directly linked to socioeconomic performance. Therefore, in this paper, we measure the coverage poverty experienced by the people. Several attempts have been done to calculate areas without coverage $[8,9]$. Effect of mobile coverage on railway network in Norway is studied in [10]. These attempts, however, do not really give an idea of quality of service experienced by the users. Therefore, to quantify the quality of service, the coverage poverty experienced by (a) people living in their apartments and (b) cars plying through the roads of Norrbotten province of Sweden is mathematically calculated.

The paper is organized as follows. A review of techniques used to analyze effect of signal strength in various conditions is provided in Section 2. A detailed explanation of generating coverage map from crowd sourced measurements is provided in Section 3. Section 4 is devoted to result analysis, while conclusions are listed in Section 5.

\section{Coverage Maps from Scattered Samples}

In this section, we elaborate the methods by which the signal strength over the populated areas and roads are analyzed using measured signal strengths. There are different ways of generating a coverage map and analyzing the signal strength: (1) identifying BS and then calculating the signal strength using factors such as path loss [11], (2) finding base station location from manually measured signal strength at different locations [12-14], and (3) generating coverage map from manually measured signal strength values. Since the locations of BS are not disclosed to public, we resort to the third method where we use tens of millions of measurements to generate coverage map. With millions of measurements, it is more likely to get a predicted signal strength than resorting to earlier methods. The signal strength measurements are taken for different operators and radio access technology (RAT) at difference time instances, which are then interpolated to form rectangular zones depicting average signal strength over that area. However, as we are only relying on available signal strength to generate coverage map, we miss lot of area as unmapped region.

2.1. Generating Coverage Map. The availability of measurements is limited to GPS coordinates on roads in general. This is because measurements are usually carried out by mobiles that are kept in the vehicles. Therefore, practically it is impossible to measure signal strength throughout the area to be mapped and identify exact signal strength at those locations. Therefore, we use the signal strength from the available signal strength measurements to calculate signal strength in the rest of the areas.

In order to generate coverage map of various RATs and operators, it is important to separate the measured signals. The measurement from mobile phones contains network type info, operator, and signal strength, based on which it is possible to filter the point to corresponding sets that represent different RATs and operators. Therefore, for each operator, sets of different RATs such as $\mathbf{S}_{\mathrm{LTE}}, \mathbf{S}_{\mathrm{UMTS}}, \mathbf{S}_{\mathrm{GSM}}$ can be made. Sets $\mathbf{S}_{\mathrm{LTE}}, \mathbf{S}_{\mathrm{UMTS}}$, and $\mathbf{S}_{\mathrm{GSM}}$ represent the sets of measurements under LTE, UMTS, and GSM, respectively. The subscripts to $\mathbf{S}$ represent different RATs.

Interpolation techniques such as kriging and inverse distance weighting [15] are widely used for obtaining coverage area map using measured signal strengths. Although different versions of kriging such as ordinary kriging and universal kriging are popular for crowd sourced measurements, a computationally less complex algorithm is used here as we consider large geographical area. In [16, 17], the authors compare kriging with IDW algorithm and find that kriging provides slightly better results compared to IDW. However, it is mentioned in [17] that the computational complexity for kriging is much higher, which is not a great concern when the area under study is small. But, as the area under study is large, computationally simple IDW algorithm is preferred over kriging to generate coverage maps for all operators and RATs.

IDW algorithm predicts the signal strength in locations where measured points are not available. IDW algorithm makes use of the fact that measurements in the near vicinity contribute better than farther points. Therefore, bigger number of measured signal strength makes the signal strength prediction more closer to a possible real measurement. It is interesting to note that the IDW algorithm produces an averaging effect on measurements that are isolated. However, in case of crowded measurements, the signal strength assigned to the polygon is affected not only by the measurements in it but also by the measurements near to it.

The output of IDW algorithm is a raster map, made up of a grid of points. These points are located at the center of each pixel, which is the basic building block of the raster. To generate a coverage map, a signal strength value is assigned to each point in the grid, based on the available signal strength values. The points in grid and measured point are marked as blue and red dots, respectively, in Figure 1. Although the IDW algorithm does not limit the number of points that are used in order to calculate the signal strength of point in the grid, since the points in the vicinity contribute more to the measurement, we restrict the search to a circle, where each point in the grid is the center of the search circle.

The points in the grid are spaced at distance $d$, which is also the length of the edge of each raster (coverage map) cell. Using Tobler's rule [18], the grid spacing $d$ is taken as

$$
d=\frac{\text { map scale }}{2 \times 1000}
$$

where map scale depends on where the points under study are spread. In effect, the length of edges of raster is dependent on the distance of right-most, left-most, top-most, and bottom-most points among the available points. 


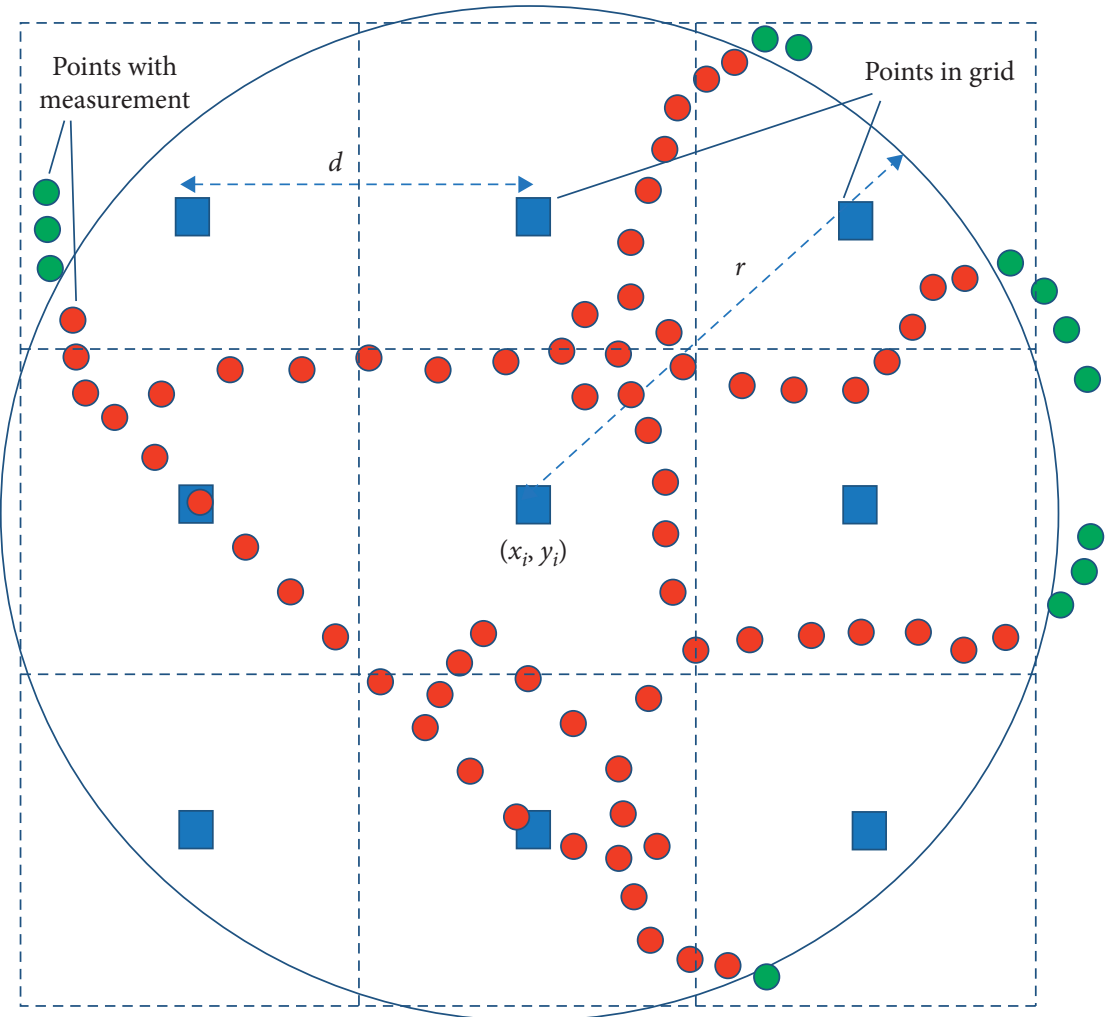

FIgURE 1: Selecting points to run IDW algorithm.

To generate the raster, each pixel or spatial object must hold the value of an element from a set $\mathbf{M}$. Therefore, an object $O$ must have two properties:

(a) A spatial extent, $Z_{i}$

(b) A function $f_{O}$ that assigns a value from set $\mathbf{M}$ to each point in $Z_{i}$

Considering the search radius $r$, object $O$ is defined as

$$
O=\left(Z_{i}, M_{i} \Psi_{r}\right)
$$

Thus, object $O$ is a tuple $\left(Z_{i}, M_{i} \Psi_{r}\right)$, where $M_{i} \in \mathbf{M}$ and $Z_{i} \subseteq \mathbf{R}^{2}$. The function $f_{O}: Z_{i} \longrightarrow \mathbf{M}$, where $\mathbf{M}=\{\mathbf{R}$, "NOSIGNAL" $\}$. In effect, the value $f_{O}\left(x_{i}, y_{i}\right)$ reflects the signal strength to be attributed to $\left(x_{i}, y_{i}\right) \in Z_{i}$. The distance, $d$, between neighbouring points in a raster, $\left(x_{i}, y_{i}\right)$, is obtained from equation (1). The signal strength $M_{i}$ for each point in raster at location $\left(x_{i}, y_{i}\right)$ is given as

$$
\begin{array}{r}
M_{i}=\frac{\sum_{\left(x_{j}, y_{j}\right) \in S} S_{j}\left(\left(x_{i}-x_{j}\right)^{2}+\left(y_{i}-y_{j}\right)^{2}\right)^{-\alpha} \Psi_{r}\left(x_{j}, y_{j}\right)}{\sum_{\left(x_{j}, y_{j}\right) \in S}\left(\left(x_{i}-x_{j}\right)^{2}+\left(y_{i}-y_{j}\right)^{2}\right)^{-\alpha}}, \\
\Psi_{r}\left(x_{j}, y_{j}\right) f_{O}\left(x_{j}, y_{j}\right)= \begin{cases}f_{O}\left(x_{j}, y_{j}\right), & \text { if } \sqrt{\left(x_{i}-x_{j}\right)^{2}+\left(y_{i}-y_{j}\right)^{2}}<r, \\
0, & \text { if } \sqrt{\left(x_{0}-x_{j}\right)^{2}+\left(y_{0}-y_{j}\right)^{2}}>r,\end{cases}
\end{array}
$$

where $S_{j} \in \mathbf{S}, \mathbf{S}=\{\mathbf{R}$, "NOSIGNAL" $\}$ and $d_{i j}$ is the Euclidean distance between measured point $j$ and point $i$ in the grid. $\alpha$ denotes the distance exponent or power index, which is taken as 2 . The characteristic function $\Psi_{r}$ is defined as in equation (4), where $r$ is the search radius. Hence, after successful implementation of (3) on $\mathbf{S}_{\mathrm{LTE}}, \mathbf{S}_{\mathrm{UMTS}}$, and $\mathbf{S}_{\mathrm{GSM}}$, we get $\mathbf{M}_{\mathrm{LTE}}, \mathbf{M}_{\mathrm{UMTS}}$, and $\mathbf{M}_{\mathrm{GSM}}$ representing the coverage map for LTE, UMTS, and GSM, respectively.
2.2. Coverage Specific Aspects. To generate coverage map of Telia, Tele2, and Telenor, for each LTE, UMTS, and GSM, IDW algorithm must be carried out to each ensemble of measurements dedicated to each of the above operators and RATs. The IDW applied to each of these groups of measurements is explained in Section 2.1. A simple IDW with all the measurements, where "NO SIGNAL" is also an entry, will generate wrong results and therefore needs to be treated separately. 
Here, we formulate a coverage specific approach to generate coverage map, by taking into account both real signal measurements and points with no signal measurements. The algorithm is represented in Figure 2. The first step is to separate points with valid signal measurements and points without signal strengths and generate coverage map for each set. These rasters or grids of points are then converted to polygons. Now, the difference between coverage maps with valid measurements and no signal strengths is created. This output is then merged to the coverage map with valid measurements.

It is still possible to have polygons with more points without signal strength and less points with valid measurements. To address such situations, a final step is required. That is, the polygon is assigned "NO SIGNAL," when the number of points without valid measurements is more even if there is a valid signal strength assigned to it. In the absence of such situations, the signal strength value assigned to the final coverage polygon remains the same as the one from the coverage map generated from valid measurements.

\section{Practical Case Study}

3.1. Measurements. In order to generate raster, we measure the signal strengths of various operators and RATs with GPS coordinates and time stamps. The measurement is made by using set of mobile phones, which are locked to specific operators and RATs. The set of mobile phones is kept in a bag as shown in Figure 3, where each phone is locked to a single operator and RAT. To this end, three operators in Sweden are compared, where Tele2 and Telenor share the same infrastructure for 2G (GSM) and 4G (LTE). Therefore, each bag contains 2 phones to measure $2 \mathrm{G}$ signal and 3 phones to measure $3 \mathrm{G}$ signal and again 2 phones to measure $4 \mathrm{G}$ signal, which records measurements at regular intervals.

We consider three operators, Telia, Tele2, and Telenor, over the Norrbotten region, which is the northernmost province in Sweden. The mobile phones that measure signal strengths are enclosed in a bag and are placed in vehicles and boats plying through the area under study. The mobile phones collect data, namely, GPS coordinates, date, time, network type, signal strength, operator, cell identification code (CID), location area code (LAC), and eNode bid at regular intervals. It is worth noting that the measurements from various phones in the bag are not time-synchronized.

The two GSM phones measure broadcast channel (BCCH) and the signal strength measured in GSM is the received signal strength indicator (RSSI). The 3G RAT used in the phones is universal mobile telecommunications system (UMTS), which is a wideband code division multiple access (WCDMA) system. Therefore, the mobile phones dedicated to measuring $3 \mathrm{G}$ signals measure the received power on one code over the primary common pilot channel (CPICH). This value is referred to as the received signal code power (RSCP). The 4G RAT is also known as the long-term evolution (LTE) standard, which uses time-frequency resource block with varying channel size (from 1.4 to $20 \mathrm{MHz}$ ). Therefore, the useful power is contributed by different resource blocks, which is measured as reference signal received power (RSRP).
The $2 \mathrm{G}$ and $3 \mathrm{G}$ phones are locked to $2 \mathrm{G}$ and $3 \mathrm{G}$ RAT, respectively. This means that the mobile phone cannot perform handover operation from $3 \mathrm{G}$ to $2 \mathrm{G}$ when it has poor signal strength. However, the $4 \mathrm{G}$ mobile phones are not locked to RATs and as a result they switch RAT from LTE to UMTS and then from UMTS to GSM based on the measured signal strength. In other words, the phones that measure LTE signals provide RSRP values in fewer areas, even though there are RSRP values when phone switches to other RATs from LTE.

The number of measurements received per municipality is given in Table 1. In this paper, we study the distribution of signal strength over residential areas and roads. The population and road lengths associated with each of the municipalities are listed in the table. The number of measurements per municipality consists of three RATs and three operators. The population map considered for analysis is a $1 \mathrm{~km} \times 1 \mathrm{~km}$ polygon shape file provided by [19]. The road data is given by [20], which provides information about number of vehicles moving through that particular road.

3.2. Framework to Analyze the Quality of Service. With the measurements in hand, this section lays the framework to analyze the distribution of signal strength over residential areas and roads. For this purpose, we use two sets of polygon files, population and road, as a base layer that extracts signal strength from the superimposed coverage map. While the first helps us to study the effect in static users, the latter provides insight into the coverage for mobile users. Further, we define different levels from LTE, UMTS, and GSM signal strength, with which the quality of service enjoyed by the users can be easily identified. The algorithm used for classification of user levels is mentioned in Figure 4 . The fact that LTE, UMTS, and GSM offer better service in the respective order is used for forming the algorithm. While RSRP $>-80 \mathrm{dBm}$ is an excellent signal strength in LTE, $-90 \mathrm{dBm}<\mathrm{RSRP}<-80 \mathrm{dBm}$ offers poorer performance than the former [21]. Therefore, we assign the former as level 1 and the latter as level 2. Following the pattern, we assign higher levels to the LTE and lower levels to UMTS [21] as the data rate decreases in UMTS compared to LTE. This pattern is repeated in GSM as well [22].

Note that the points labelled No Signal and NULL are not considered while assigning levels till level 12, where No Signal represents a situation where UEs did not receive any signal, whereas NULL considers a scenario where polygon does not have a signal strength to map to. Level 13 is used to represent the signal strength that is lesser than the minimum required signal strength for a reliable communication. A scenario where the UE cannot make call in any of the RAT is considered in level 14. The difference between level 13 and level 14 is that connection is not possible in level 14 , while connection may be possible with possible chance of disconnection in level 13 [21, 23]. For example, if the device under test has LTE signal strength below $-100 \mathrm{dBm}$, UMTS signal strength below $-85 \mathrm{dBm}$, and GSM signal strength below $-110 \mathrm{dBm}$, the signal strength values in mobile 


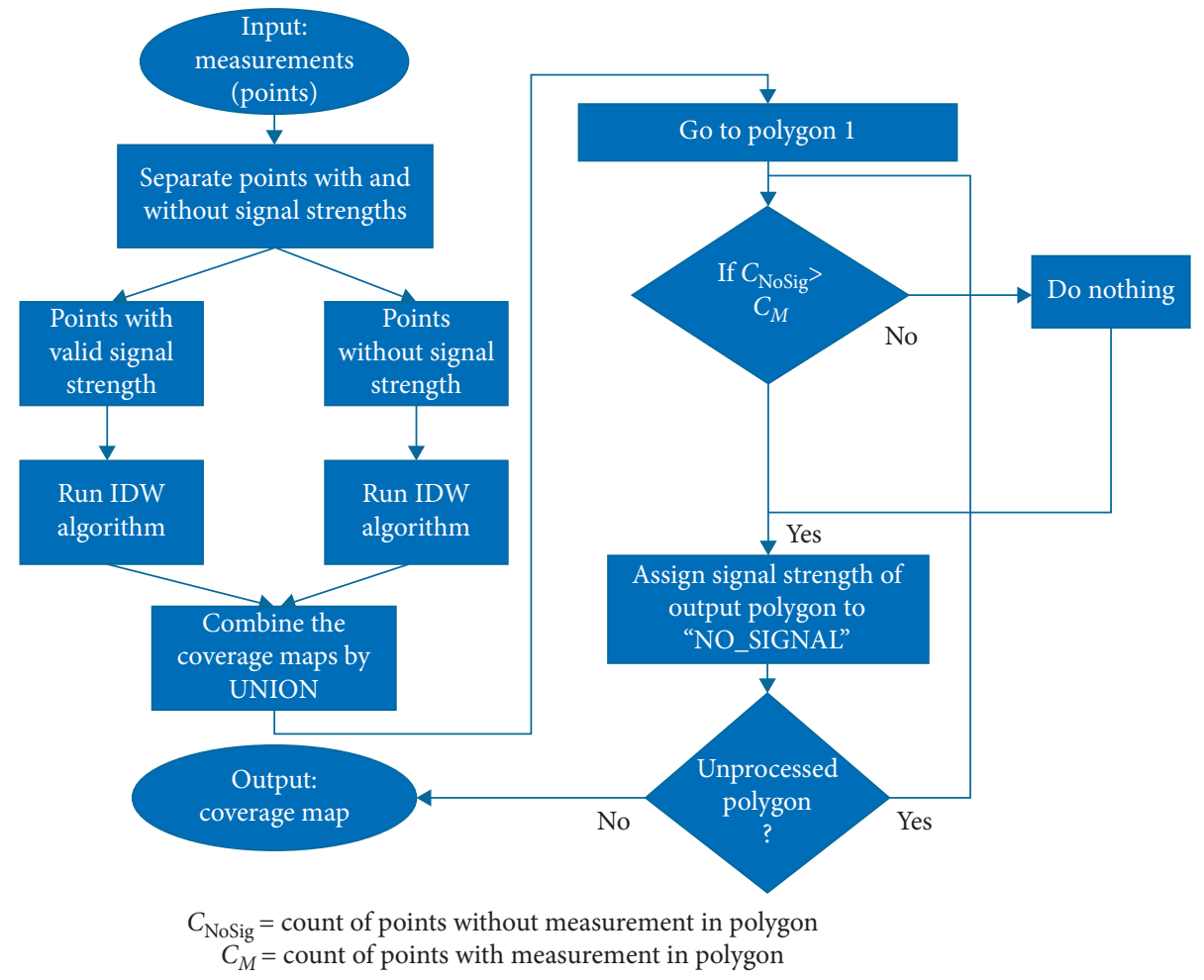

Figure 2: Algorithm to generate coverage map.

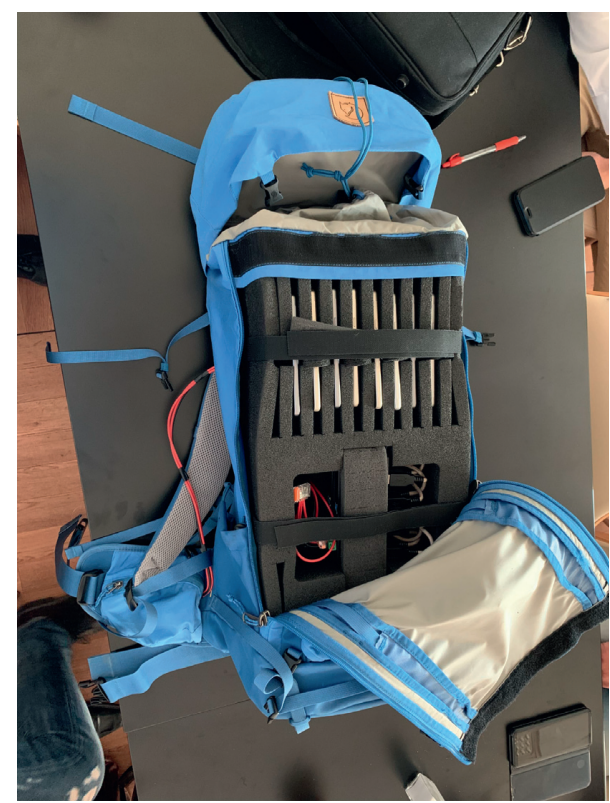

Figure 3: Measurement setup by IQMTEL, Sweden.

phones fall below the minimum recommended signal strength [21, 23]. Such a situation is possible in level 13 . Meanwhile, if all devices are not getting any signal from the base station, we assign level 14, which is the worst situation among all. Level 15 does not represent the quality of the signal, as it houses the regions where the measurement campaign was not performed.
TABle 1: Measurements across municipalities of Norrbotten.

\begin{tabular}{lccccc}
\hline $\begin{array}{l}\text { SI. } \\
\text { no. }\end{array}$ & Municipality & $\begin{array}{c}\text { No. of } \\
\text { measurements }\end{array}$ & $\begin{array}{c}\text { Area } \\
\left(\mathrm{km}^{2}\right)\end{array}$ & Population & $\begin{array}{c}\text { Road } \\
(\mathrm{km})\end{array}$ \\
\hline 1 & Älvsbyn & 708191 & 1790.4 & 8256 & 530.1 \\
2 & Arjeplog & 887558 & 14498.3 & 2903 & 720.1 \\
3 & Arvidsjaur & 1826754 & 6085.7 & 6490 & 1019.9 \\
4 & Boden & 2409219 & 4277.1 & 28373 & 875.9 \\
5 & Haparanda & 378870 & 16806.7 & 9851 & 284.6 \\
6 & Jokkmokk & 2089506 & 933.2 & 5132 & 796.3 \\
7 & Kalix & 940068 & 19314.4 & 16240 & 652.7 \\
8 & Luleå & 4603223 & 1850.3 & 78160 & 767 \\
9 & Pajala & 1821622 & 20642.3 & 6157 & 1004.5 \\
10 & Piteå & 3883938 & 2155.8 & 41932 & 919.6 \\
11 & Gällivare & 3070680 & 2913.9 & 18023 & 976.6 \\
12 & Kiruna & 2315800 & 2515.7 & 23233 & 730.1 \\
13 & Överkalix & 325123 & 8103.7 & 3409 & 521.7 \\
14 & Övertorneå & 671210 & 3246.1 & 4582 & 556.1 \\
\hline
\end{tabular}

3.2.1. Framework to Analyze Effects in Residential Areas. In this subsection, we study the effect of signal strength on users in residential areas. Figure 5 demonstrates the extraction of signal strength from the coverage map. The upper layer is the coverage map, which holds the signal strength value. The lower layer, which is population map in this contest, extracts signal strength from the overlapping coverage map and adds the signal strength value $M_{k}$ to each polygon of the population or road map.

In order to extract $M_{k}$ from an overlapping coverage map, each polygon uses the settings in Table 2 , which is executed using QGIS, a free geographic information 


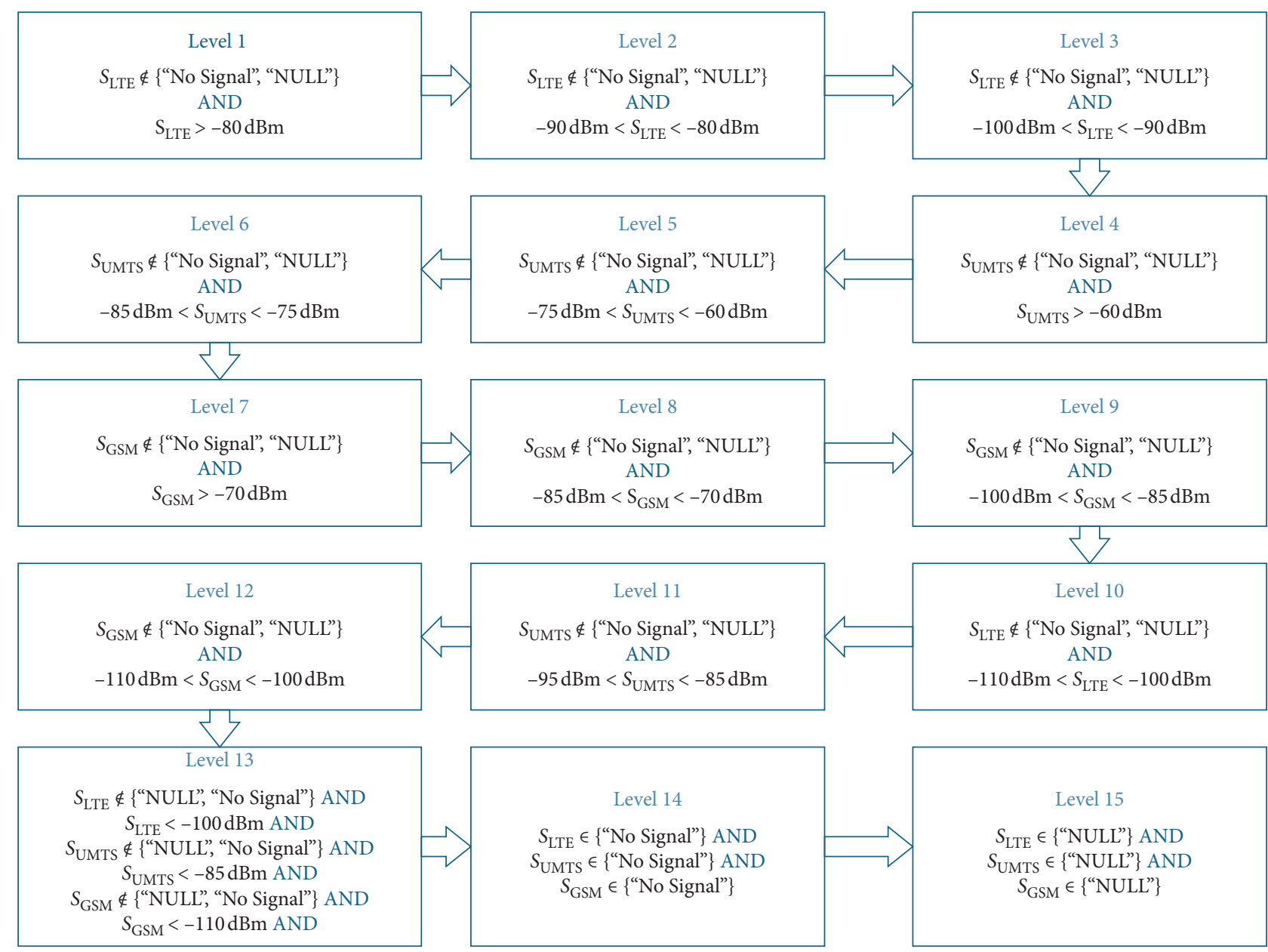

FIgure 4: Assigning signal levels.

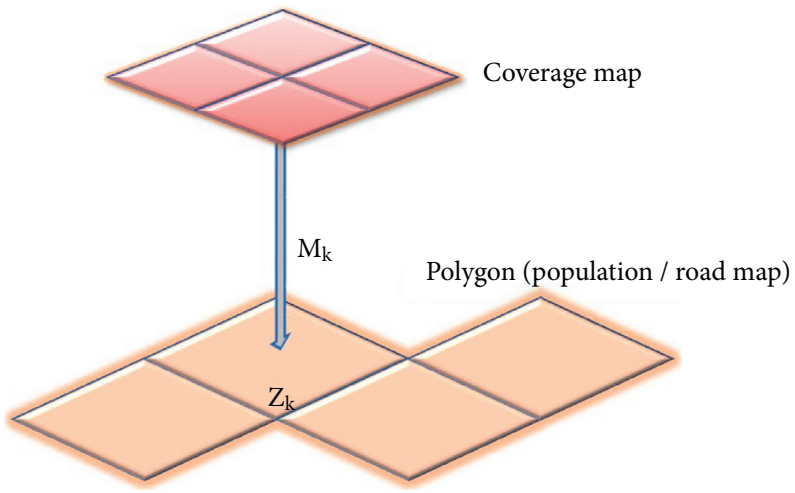

FIgURE 5: Extracting signal strength from coverage map.

system (GIS) software. That is, the polygon in population or road map considers those signal strengths from the overlapping coverage map, when the polygon in coverage map intersects with it. In case the population or road map polygon intersects with multiple polygons of the coverage map, the algorithm selects one random value among them, thereby creating a one-to-one mapping with each polygon in population or road map and signal strength value.
3.2.2. Framework to Analyze Effects in Roads. Since the roads can stretch to few kilometers and assigning signal strength to each line is impossible, we split the lines representing roads to segments of $100 \mathrm{~m}$ or less, for absorbing information from overlapping coverage map. For example, a road whose length is $1.050 \mathrm{~km}$ is divided into 10 units, each of $100 \mathrm{~m}$ and one unit of length $50 \mathrm{~m}$. The contribution of the unit of length $x$, where $x<100 \mathrm{~m}$, is taken as $x / 100$ while calculating total number of segments 
TABLE 2: Feature extraction.

\begin{tabular}{lcc}
\hline SI. no. & Option & Setting in algorithm \\
\hline 1 & Geometric predicate & Intersect \\
2 & Mapping (join type) & One-to-one \\
3 & Fields to add & Signal strength \\
\hline
\end{tabular}

in a particular level. Signal strength value is extracted from overlapping coverage map of each RAT, $\mathbf{S}_{\mathrm{LTE}}, \mathbf{S}_{\mathrm{UMTS}}$, and $\mathbf{S}_{\mathrm{GSM}}$, and is assigned to each line segment. As a result, in addition to signal strength value, the line segment object also carries the length of each segment. The line segment extracts signal strength value from overlapped coverage map (M) with the settings shown in Table 2 . As a result, each line segment object $q$ is a tuple $\left(Z_{q}, M q, l_{q}\right)$, where $l_{q}$ is the length of the line segment $q$.

Furthermore, to analyze the performance of various operators to users on road, we define two variables, $\lambda_{q}$ and $\phi_{q}$. The basic logic here is that the coverage poverty experienced by 100 cars in $1 \mathrm{~km}$ is the same as that of 1 car in $100 \mathrm{~km}$. Therefore, to quantify the coverage poverty, we multiply the number of cars moving through segment $q$ with $l_{q}$. Also, to incorporate smaller road segments, we normalize the product by length. Therefore, we define $\lambda$ for segment $q$ :

$$
\lambda q=\frac{\text { number of cars through } q \times l_{q}}{100} .
$$

Since different roads have speed limits, we must add this factor into consideration, as the vehicle stays on road for more time in poor coverage areas. Therefore, we define another parameter:

$$
\phi q=\frac{\lambda q \times 3600}{1000}
$$

where the numerator specifies the speed in $(\mathrm{km} / \mathrm{hr})$ and to convert it to $(\mathrm{m} / \mathrm{s})$ and we multiply the term by 3.6 . These two variables quantify the coverage poverty of absence of coverage to the users.

\section{Data Analysis}

4.1. Signal Strength across Residential Areas in Municipalities. Histogram of signal strength is analyzed for various RATs and operators. For the ease of comparison, we consider LTE by Telia in Lulea and Pajala, a comparatively densely populated municipality and a sparsely populated municipality, respectively. Further, the histogram of GSM signal strength is plotted and compared with that of LTE.

Figure 6 shows histogram of GSM signal strength, where the height of each bar shows the percentage of people falling in the respective slot. Both municipalities have maximum number of people in $-70 \mathrm{dBm}$ to $-60 \mathrm{dBm}$ range for GSM. Also, the range is the same for most of the municipalities.

From Figure 7, we can see that the behaviour in LTE is similar to that of GSM, but majority of people fall in $-100 \mathrm{dBm}$ to $-90 \mathrm{dBm}$ range. Most of the municipalities show similar behaviour. It is visible that there is a shift in mostly used signal strength in GSM and LTE. That is, from Figure 4 , it is known that $-70 \mathrm{dBm}$ to $-60 \mathrm{dBm}$ range in RSSI is an excellent GSM signal strength, and $-100 \mathrm{dBm}$ to $-90 \mathrm{dBm}$ LTE signal strength offers only fair service to the users. On the contrary, the quality of service offered by LTE for signal strength from $-100 \mathrm{dBm}$ to $-90 \mathrm{dBm}$ is still better than GSM signal strength of $-70 \mathrm{dBm}$ to $-60 \mathrm{dBm}$.

\subsection{Signal Strength across Roads in Municipalities.} Figure 8 shows the histogram of signal strength for Telia GSM. For fair comparison of histograms generated for residential areas, we consider the same municipalities, Lulea and Pajala. Unlike residential areas, where both municipalities have maximum number of people in $-70 \mathrm{dBm}$ to $-60 \mathrm{dBm}$ range for GSM, roads of these municipalities have maximum number of people in $-90 \mathrm{dBm}$ to $-80 \mathrm{dBm}$ and $-80 \mathrm{dBm}$ to $-70 \mathrm{dBm}$ ranges, respectively. It is observed that this shift is common for most of the municipalities. Another interesting observation is that the sparsely populated municipality, Pajala, has better signal strength in most of its roads, despite the low population density.

The LTE signal strength in roads of Pajala is reported in Figure 9. Compared to Figure 8, a decrease in signal strength is observed. Although there is a dip in average signal strength in LTE, the performance at the user end is still better than that of GSM. Unlike the histograms of residential areas, where the absence of measurement ("No Data") is almost zero, the percentage of roads without measurement is bigger. This is mainly due to the mode of measurement, where the measurements are taken by phones placed in mostly public utility vehicles.

4.3. Effect of Traffic Pattern. In this subsection, we quantify the effect of $3 G$ signal strength on users on roads. Figure 10 (a) plots histogram of $\lambda$, where $\lambda=\left\{\lambda_{q}\right\}$, for various $3 \mathrm{G}$ operators in Jokkmokk. With this approach, the best operator can be identified. Similarly, Figure 10(b) plots histogram of $\phi$, where $\phi=\left\{\phi_{q}\right\}$, for various $3 \mathrm{G}$ operators in Jokkmokk. While the latter gives the idea about temporal signal quality experienced by an average user in car, the former shows the number of cars experiencing the signal strength. However, both figures have more or less the same pattern.

4.4. Quantifying the Coverage Poverty. It is quite clear that different municipalities get affected in different levels. A low signal strength in highly populated municipality will have huge impact compared to a less populated area. Figure 11 analyzes average GSM signal strength of Telia on total population of municipalities. While the position of circles represents the mean signal strength and percentage of people without service, the radius of the circles in scatter plot shows 


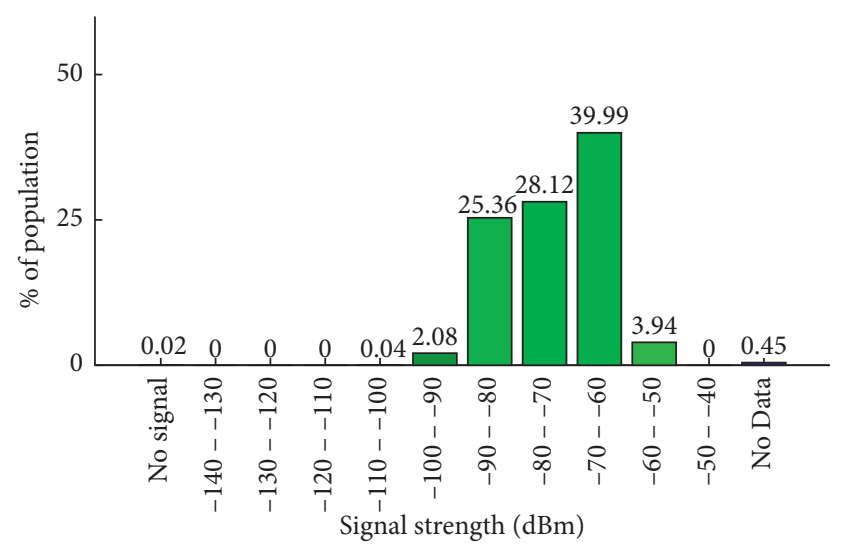

(a)

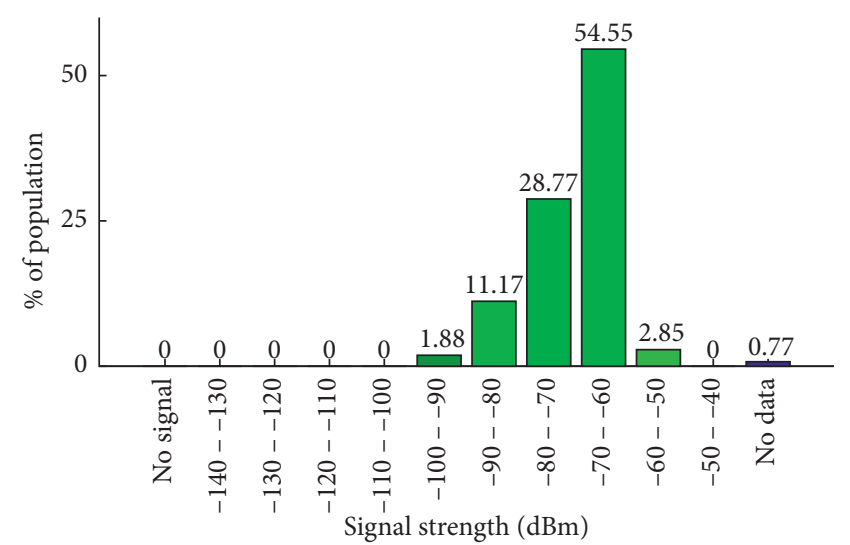

(b)

Figure 6: GSM coverage in residential areas. (a) Coverage in residential areas of Lulea. (b) 2G Coverage in residential areas of Pajala.

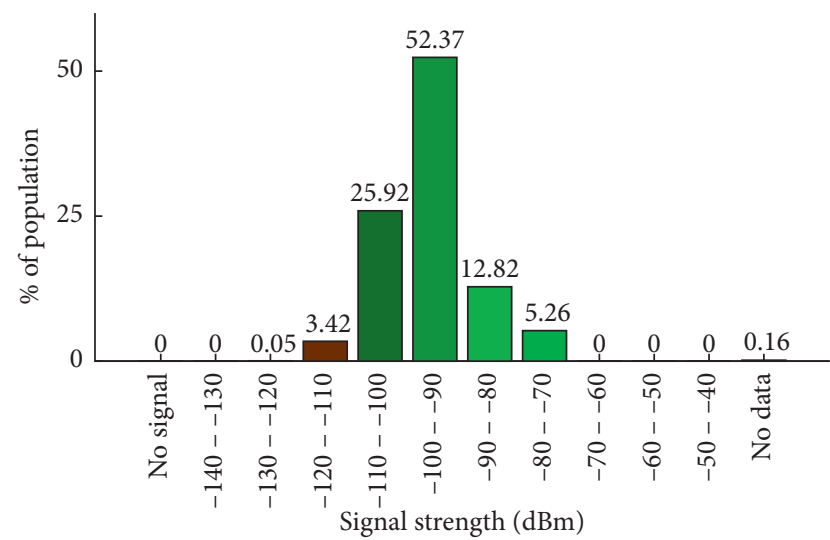

(a)

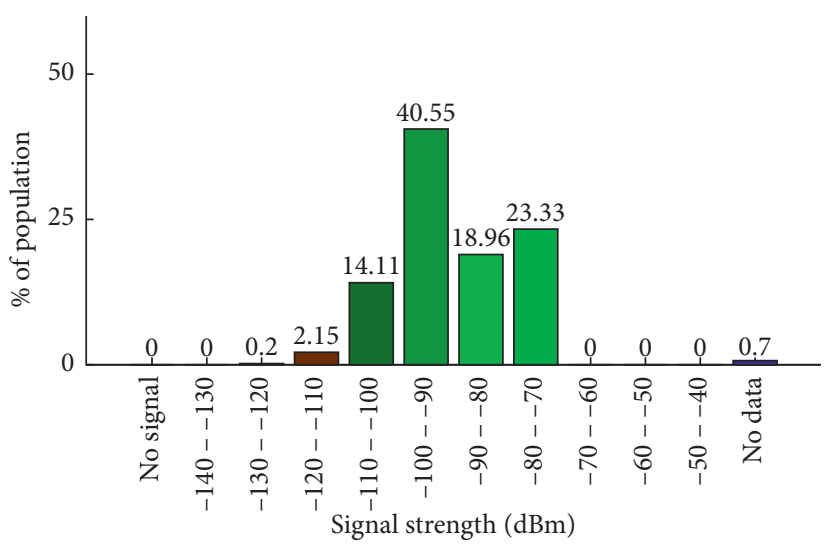

(b)

Figure 7: LTE coverage in residential areas. (a) 4G coverage in residential areas of Lulea. (b) 4G Coverage in residential areas of Pajala.

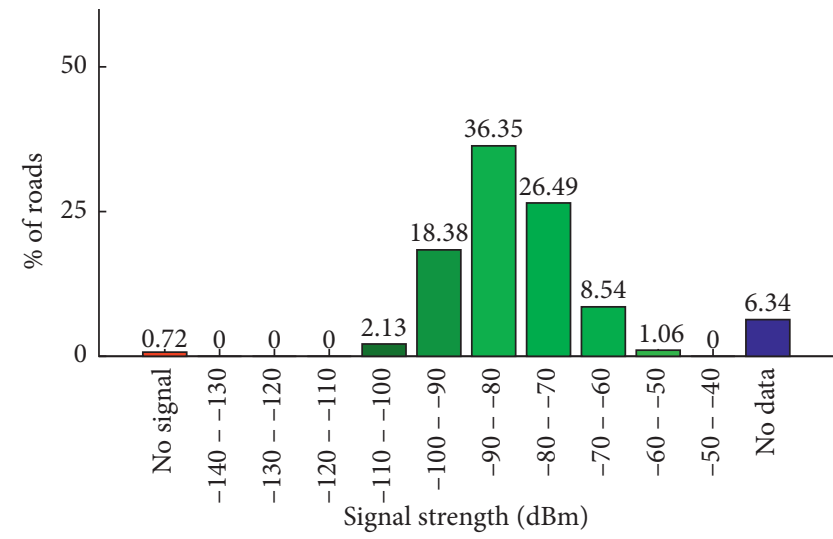

(a)

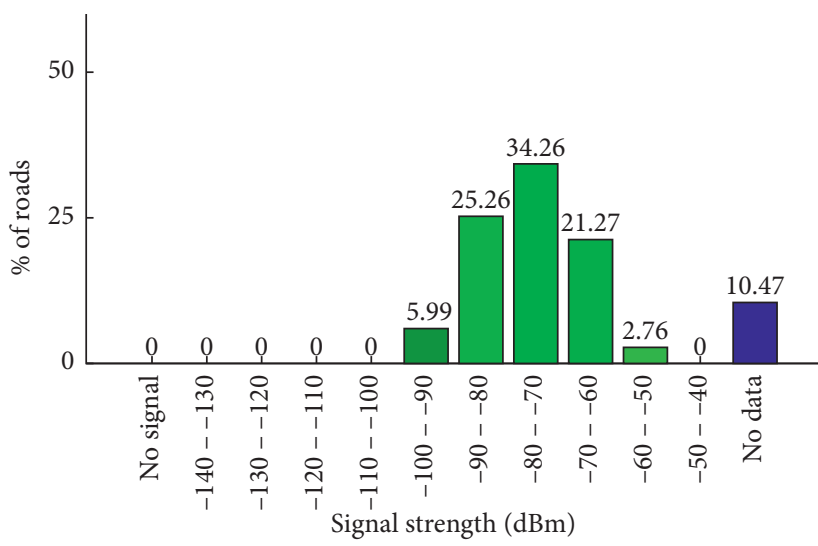

(b)

Figure 8: GSM coverage on roads. (a) Coverage on roads of Lulea. (b) Coverage on roads of Pajala.

the population or total road length in respective municipalities. Figure 11(a) reports the percentage of population without signal versus mean signal strength with GSM. It is clear that most of the users in residential areas enjoy fairquality GSM signal. Most of the populated municipalities have decent signal quality. Also, a very small percentage (less 


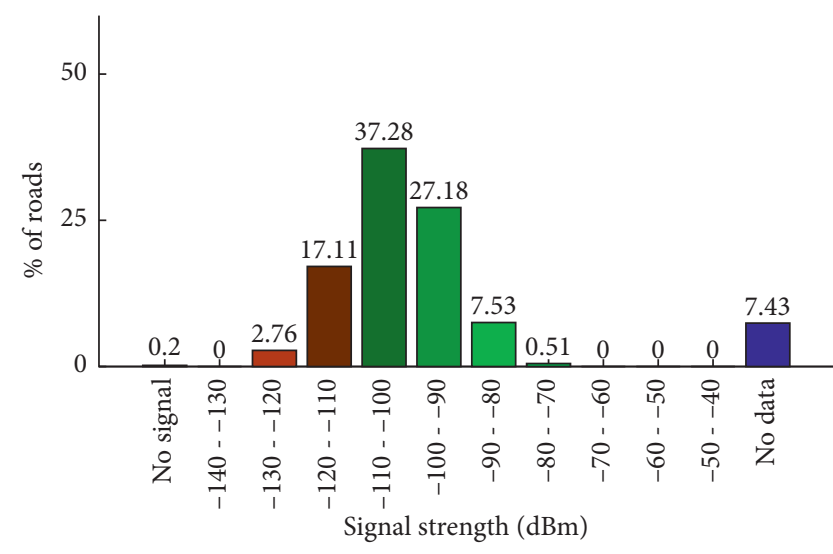

(a)

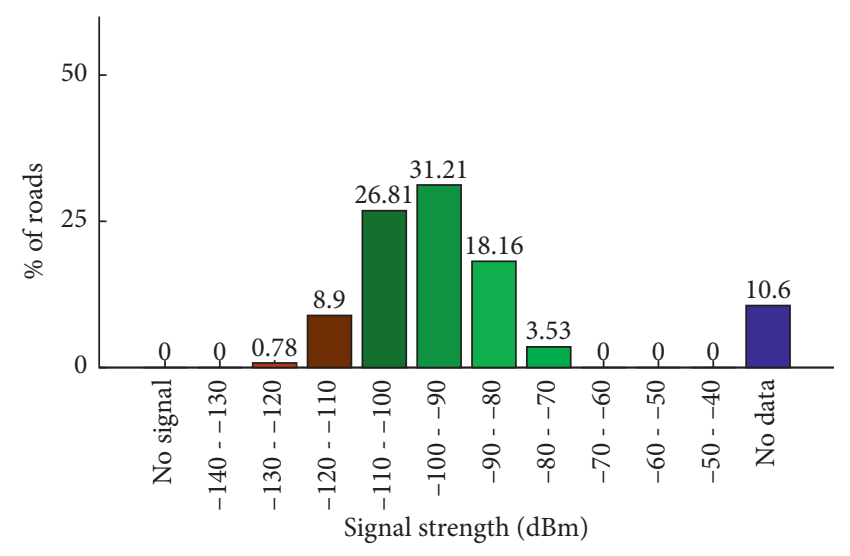

(b)

Figure 9: LTE coverage on roads. (a) Coverage on roads of Lulea. (b) Coverage on roads of Pajala.
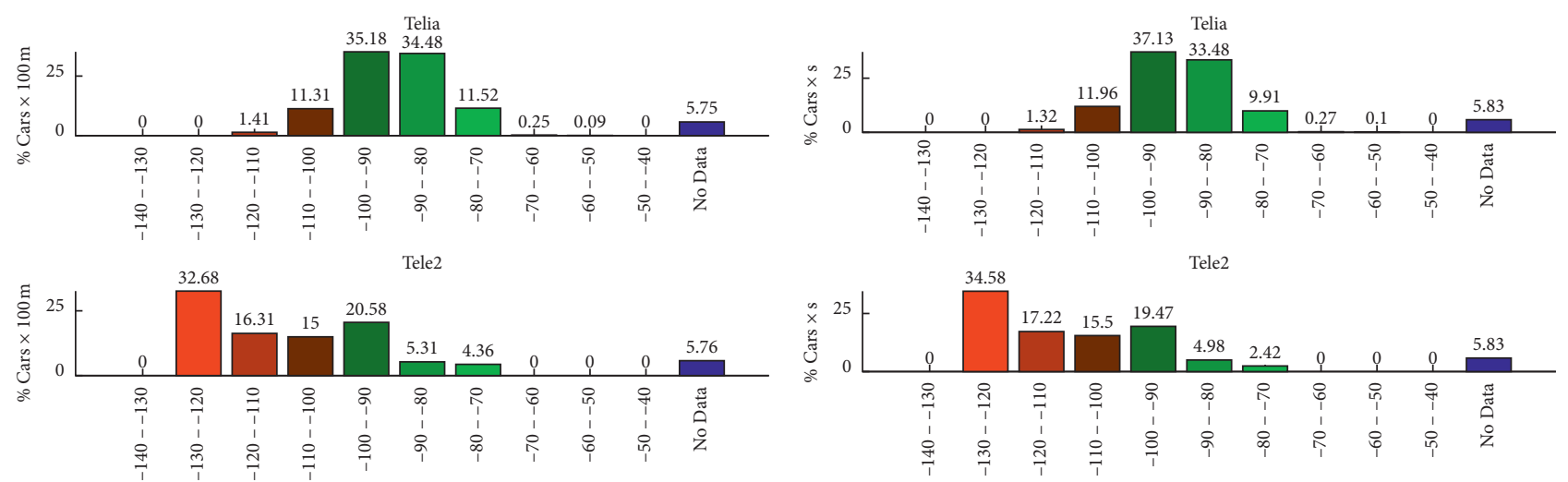

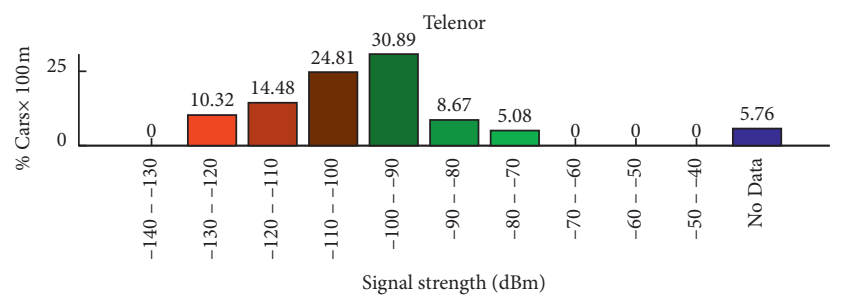

(a)

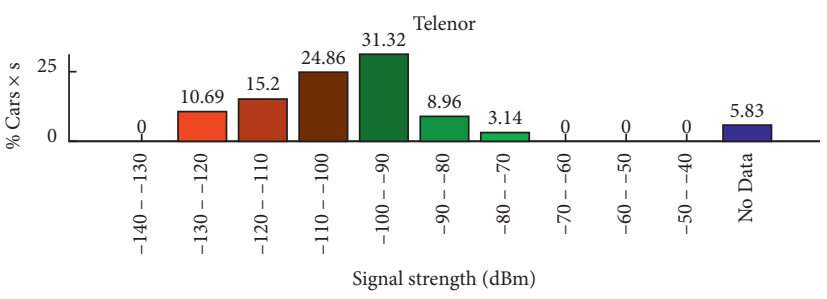

(b)

Figure 10: Effect of traffic pattern. (a) Cars $\times 100 \mathrm{~m}$. (b) Cars $\times$ sec.

than 1.5) of residential area is not covered. However, on analyzing signal strength on roads, in Figure 11(b), a decline in signal strength is observed. Although majority of municipalities get most of their roads under coverage area, there are municipalities like Övertorneå, where considerable fractions of roads are not covered.

\subsection{Signal Strength in Urban, Suburban, and Rest of the Areas.} The effect of signal strength to users in residential areas in urban, suburban, and rest of the areas is reported in Figure 12. The term rest of the areas is used to denote residential areas that do not fall under urban or suburban category. The CDF of population is plotted against GSM signal strength. While GSM offers best signal strength in urban areas, the medium and least signal strengths are observed in suburban areas and rest of the areas, respectively. A fraction of population is under no coverage area of Tele 2 and Telenor in suburban areas and rest of the areas. However, despite the region classification, Telia offers $1-4 \mathrm{~dB}$ better signal to users. It is also important to note that the results in Figure 12 are based only on the available data. We have not considered areas without measurements for analysis.

4.6. Comparison with Another County. GSM signal strengths of two different counties in Sweden, Norrbotten and Östergötland, are compared in Figure 13. We compare the signal strengths observed in urban and suburban areas of both counties. From Figure 13(a), it is clear that, despite of the county, the signal strength in urban areas remains the same. However, from 13(b), it can be observed that the user 


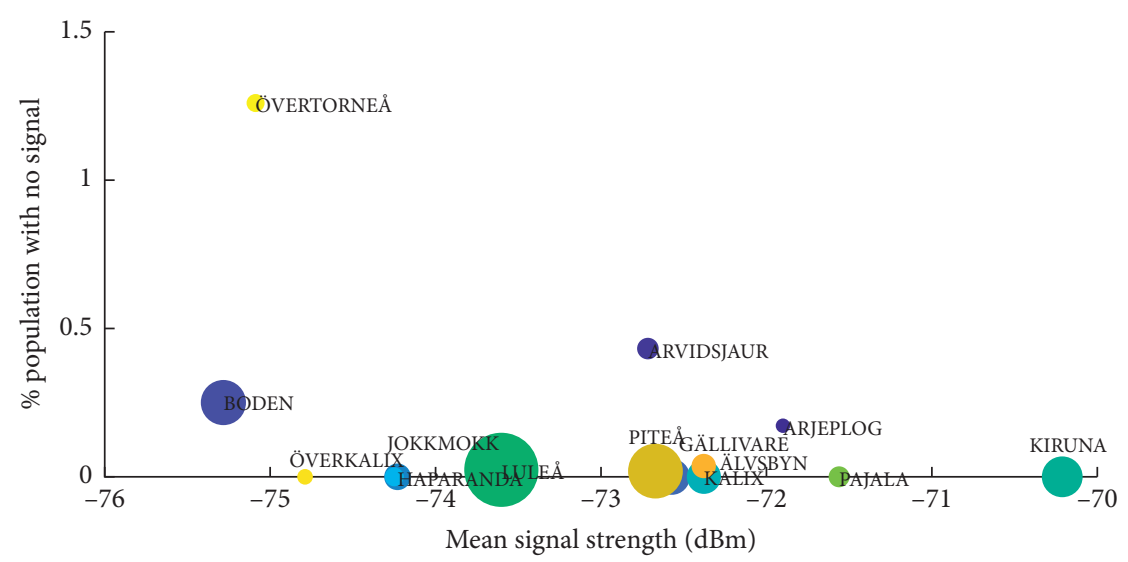

(a)

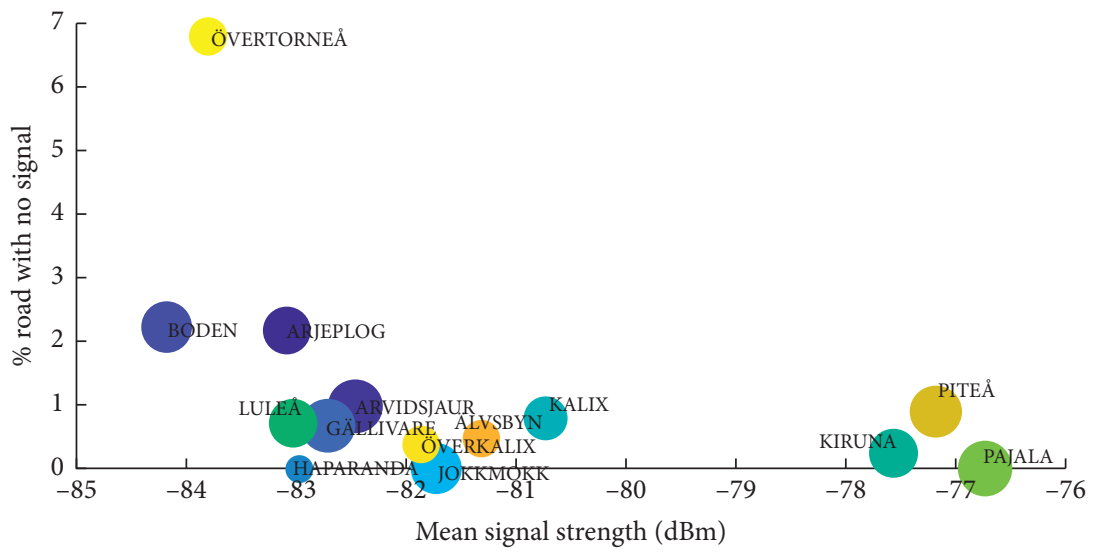

(b)

Figure 11: Impact on \% of roads/population in Telia. (a) Residence area. (b) Roads.

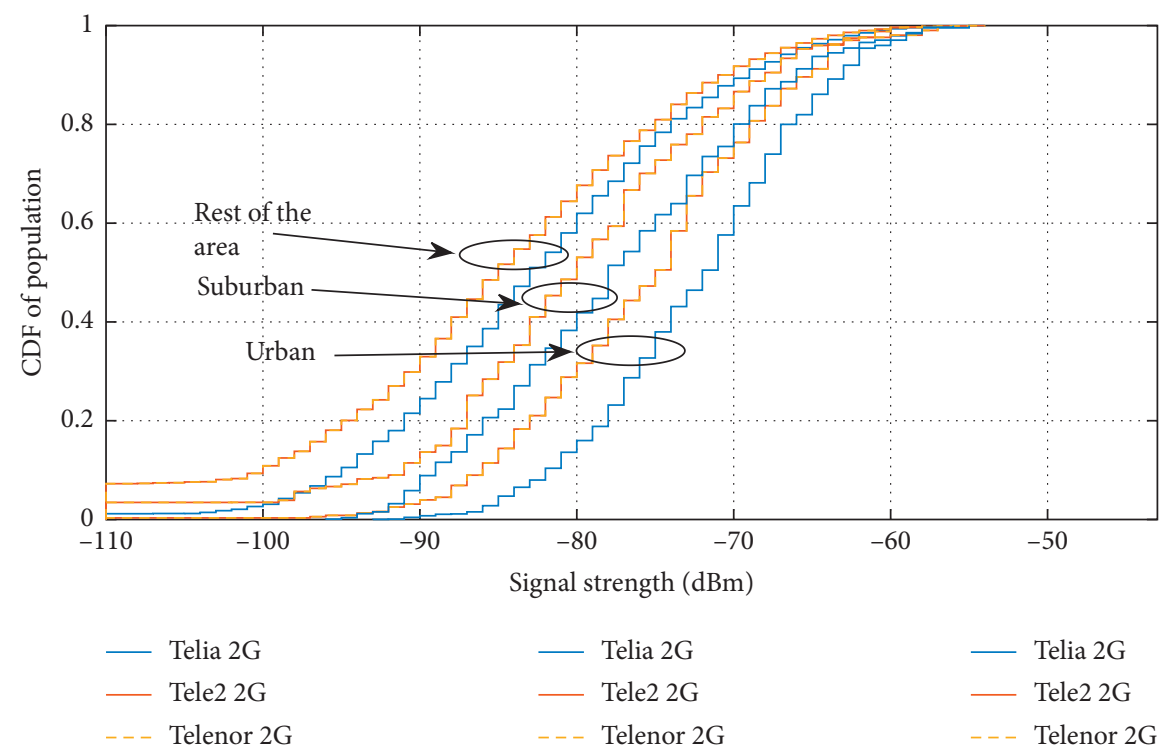

Figure 12: Signal strength in urban, suburban, and rest of the areas. 


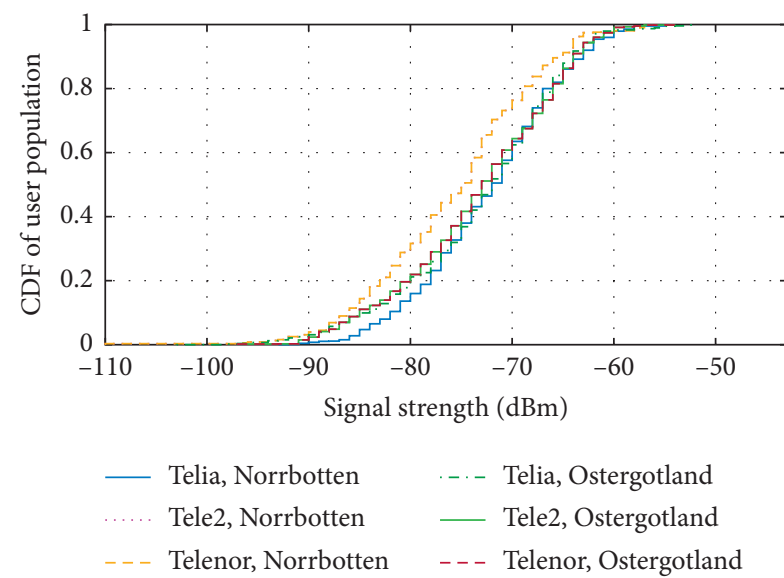

(a)

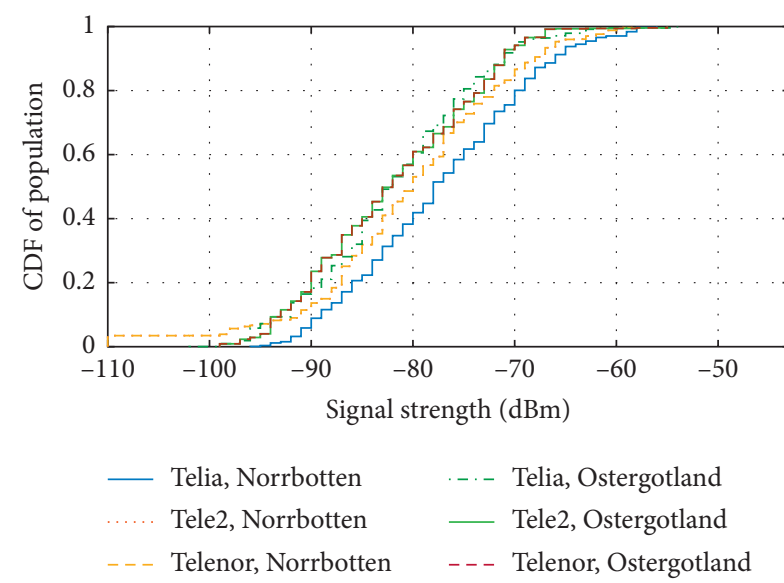

(b)

FIGURE 13: Coverage in Norrbotten and Östergötland. (a) Östergötland (urban). (b) Norrbotten (suburban).
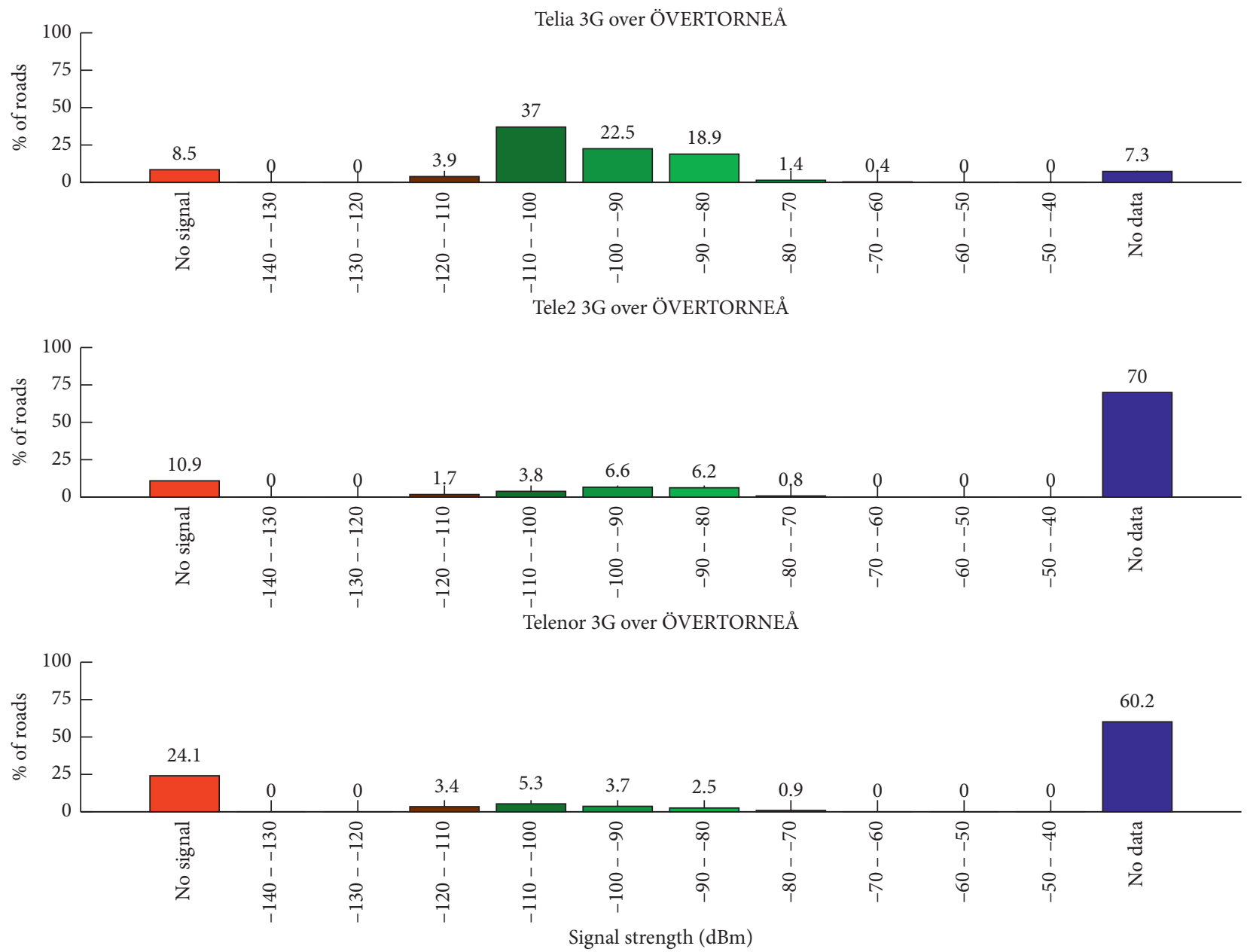

FIGURE 14: Histogram of $3 G$ signal strength in roads of Övertorneå.

gets 5 to $10 \mathrm{~dB}$ signal strength reduction, when the user moves from urban to suburban area.

4.7. Effect of Roaming. It is observed that some areas near Finland are not getting service by Tele2 and Telenor.
Although these areas are in Sweden, Tele2 and Telenor switch the call to another operator from Finland, forming large areas without measurements from Tele 2 and Telenor. Telia, on the other hand, offers connectivity from Sweden. Figure 14 shows the histogram of $3 \mathrm{G}$ signal strength in roads of Övertorneå. It is seen that $70 \%$ of roads and $60.2 \%$ of 


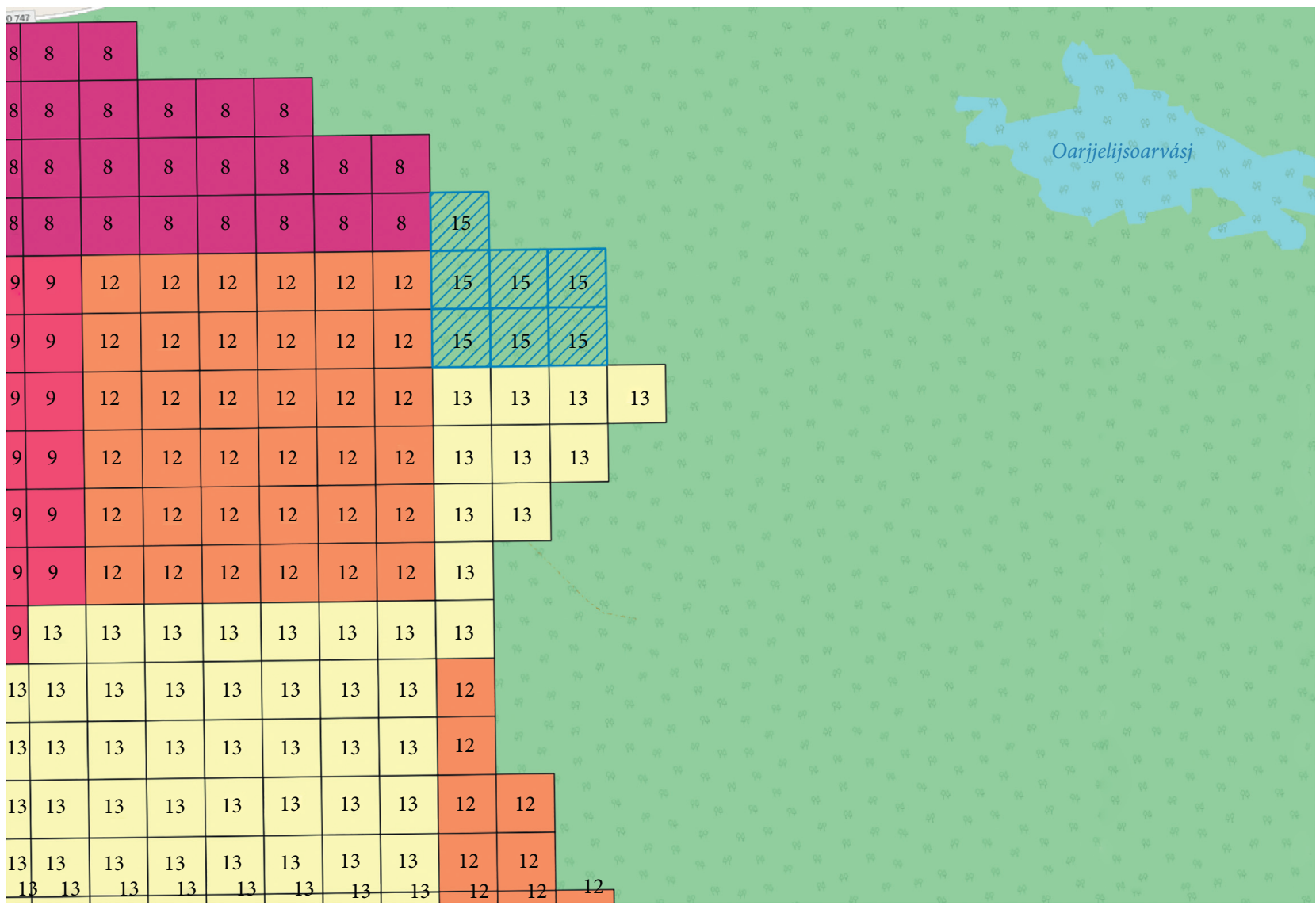

Level mapping

1 Best
2
3
$\square$
4
5

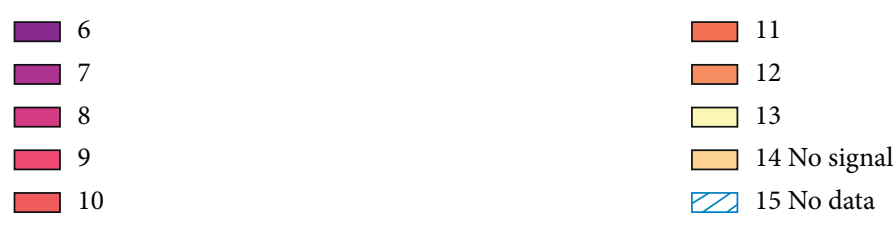

Figure 15: Correlation with $700 \mathrm{MHz}$ spectrum's focus area map.

roads from Tele 2 and Telenor are under "No Data" bin. This is because there is no measurement from Tele 2 and Telenor in majority of roads and Tele 2 and Telenor transfer the call to Elisa, a Finnish operator.

4.8. Correlation with $700 \mathrm{MHz}$ Spectrum's Focus Areas. Recently $700 \mathrm{MHz}$ spectrum has been allocated to certain areas of focus [6]. Figure 15 presents the correlation of Telia's coverage map developed using algorithm presented in Figure 2 and focus areas of new $700 \mathrm{MHz}$ spectrum, represented by rectangles. Different colours are assigned to each of the locations based on the signal quality, from level 1, which is the best, to level 14, which is the worst. A major portion of the focus area does not intersect with our map due to lack of measurements and is shown in dashed lines. On comparing the focus areas provided with our coverage map, we found that $44.1 \%$ of the areas that are intersected with our map experience poor signal (below level 10). Around 54.7\% of areas that are intersected with our map experience below-average signal (level 8-9).

\section{Conclusions}

This paper has presented a framework for analyzing mobile signal strength experienced by users. Based on measured signal strength, a coverage map has been made via IDW interpolation. Various analyses are carried out on signal strength over residential areas and roads of Norrbotten. Further, measurements are compared to those of Östergötland and it was found that both municipalities have almost similar measurements.

By analyzing coverage across all 14 municipalities of Norrbotten, in contrast to the suspicion that rural areas have poor signal strength, we found that $2 \mathrm{G}$ and $4 \mathrm{G}$ provide satisfactory results. However, $3 \mathrm{G}$ fails to provide coverage in some areas. This is worse in some areas, resulting in more than $50 \%$ of areas to be outside coverage area at some places. These areas are mostly near the Finland border, which results 
in the fact that roaming and additional charges may be applicable to the $3 \mathrm{G}$ user in these areas.

\section{Data Availability}

The cellular coverage data used to support the findings of this study have not been made available yet, as commercial interests of the supplier prevent this.

\section{Conflicts of Interest}

The authors declare that they have no conflicts of interest.

\section{Acknowledgments}

The authors gratefully acknowledge the financial support for this work from the Norrbotten County Council, along with the relentless efforts from Johanna Lindberg, without whose support this paper would have not been written. The authors also thank here the people involved in the project \#fulltäckning, with financial support by Vinnova, Norrbotten County Council, and Västerbotten County Council.

\section{References}

[1] H. Zhang, N. Liu, X. Chu, K. Long, A.-H. Aghvami, and V. C. M. Leung, "Network slicing based $5 \mathrm{G}$ and future mobile networks: mobility, resource management, and challenges," IEEE Communications Magazine, vol. 55, no. 8, pp. 138-145, 2017.

[2] "Telia Company and Lule A University of Technology Inaugurate 5G-Testbed," 2019, https://www.teliacompany.com/ en/news/news-articles/2019/5g-testbed-lulea/.

[3] H. D. Gadi, R. V. Murthy, R. Shanker, and V. Nagadevara, "Antennae location methodology for a telecom operator in India," in IIM Bangalore Research Paper 454, 2014.

[4] J. van de Beek, "Mobile broadband access in Norrbotten," 2019, https://www.norrbotten.se/publika/lg/regio/ Digitalisering/mobile-broadband-access-in-norrbottenKLAR-NY.pdf.

[5] S. A. Hadiwardoyo, C. T. Calafate, J.-C. Cano et al., "Three dimensional uav positioning for dynamic uav-to-car communications," Sensors, vol. 20, no. 2, p. 356, 2020.

[6] "Assignment decision to use radio transmitters in the 700 MHz band," 2019, https://pts.se/sv/dokument/beslut/radio/ 2018/tilldelningsbeslut-tillstand-att-anvanda-radiosandare-i700-mhz-bandet---telia-sverige-ab/.

[7] P. Koutroumpis and A. Leiponen, "Crowdsourcing mobile coverage," Telecommunications Policy, vol. 40, no. 6, pp. 532-544, 2016.

[8] D. Baltrunas, E. Ahmed, and A. Kvalbein, "Measuring the reliability of mobile broadband networks," in Proceedings of the 2014 Conference on Internet Measurement Conference, pp. 45-58, ACM, Vancouver, Canada, November 2014.

[9] J. Ponce-Rojas, S. Vidal-Beltrán, M. A. Acevedo-Mosqueda, and M. Jimenez-Licea, "A geographic information system applied to coverage maps of $3 \mathrm{~g}$ cellular communications networks," Journal of Geographic Information System, vol. 03, no. 2, p. 140, 2011.

[10] A. Lutu, Y. R. Siwakoti, Ö. Alay, D. Baltrūnas, and A. Elmokashfi, "The good, the bad and the implications of profiling mobile broadband coverage," Computer Networks, vol. 107, pp. 76-93, 2016.
[11] X. Chen, H. Wu, and T. M. Tri, "Field strength prediction of mobile communication network based on GIS," Geo-Spatial Information Science, vol. 15, no. 3, pp. 199-206, 2012.

[12] L. Sheynblat and T. Wrappe, "Method and apparatus for determining location of a base station using a plurality of mobile stations in a wireless mobile network," US Patent 7,319,878, 2008.

[13] W. Riley, R. Girerd, and Z. Biacs, "Use of mobile stations for determination of base station location parameters in a wireless mobile communication system," US Patent 7,127,257, 2006.

[14] H. Wang, S. Xie, K. Li, and M. Ahmad, "Big data-driven cellular information detection and coverage identification," Sensors, vol. 19, no. 4, p. 937, 2019.

[15] Z. Zhou, M. Zhang, Y. Wang, C. Wang, and M. Ma, “Application of Kriging algorithm based on ACFPSO in geomagnetic data interpolation," Mathematical Problems in Engineering, vol. 2019, Article ID 1574918, 14 pages, 2019.

[16] M. Molinari, M.-R. Fida, M. K. Marina, and A. Pescape, "Spatial interpolation based cellular coverage prediction with crowdsourced measurements," in Proceedings of the 2015 ACM SIGCOMM Workshop on Crowdsourcing and Crowdsharing of Big (Internet) Data, pp. 33-38, ACM, London, UK, August, 2015.

[17] Z. El-friakh, A. Voicu, S. Shabani, L. Simic, and P. Mahonen, "Crowdsourced indoor wi-fi REMs: does the spatial interpolation method matter?" in Proceedings of the 2018 IEEE International Symposium on Dynamic Spectrum Access Networks (DySPAN), pp. 1-10, IEEE, Seoul, South Korea, October 2018.

[18] W. Tobler, "Measuring spatial resolution," in Proceedings of the International Workshop on Geographic Information Systems, vol. 48, International Geographic Union, Commission on Geographical Information, Beijing, China, 1987.

[19] “Total Befolkning Per Ruta," 2016, https://www.scb.se/hittastatistik/regional-statistik-och-kartor/geodata/oppnageodata/total-befolkning-per-ruta/.

[20] "Norrbotten Trafikdata," 2017, https://www.trafikverket.se/ lastkajen/.

[21] "Mobile signal strength recommendations," 2018, https:// wiki.teltonika.lt/view/Mobile_Signal_Strength_ Recommendations.

[22] E. Leonard, R. Rainbow, J. Trindall et al., Accelerating Precision Agriculture to Decision Agriculture: Enabling Digital Agriculture in Australia, Cotton Research and Development Corporation, Narrabri, Australia, 2017.

[23] "Electronics communication committee report," 2016, https:// docdb.cept.org/download/494da92a-263a/ECCRep256.pdf. 